\title{
Escolhas na adolescência: Implicações contemporâneas dos grupos sociais e da família
}

\author{
Choices in adolescence: Contemporary implications of social groups and family
}

Carlos Alberto Ribeiro ${ }^{\dagger *}$, Fátima Niemeyer da Rocha

Como citar esse artigo. Ribeiro, C.A.; da Rocha, F.N. Escolhas na adolescência: Implicações contemporâneas dos grupos sociais e da família. Revista Mosaico. 2017 Jul./Dez.; 08 (2): 39-47.

\begin{abstract}
Resumo
As teorias psicológicas tradicionais enfatizam a adolescência como uma fase natural do desenvolvimento, com problemas e conflitos próprios à natureza humana. Tal concepção é contestada, por exemplo, por Lev Vygotsky, que considera o processo histórico-social vivido pelo indivíduo influindo diretamente na adolescência, pelas modificações introduzidas na sociedade. A partir do senso comum são assimiladas, sem que haja qualquer crítica pessoal, supostas "verdades", construídas ao longo do tempo, como a crença de que a adolescência é uma fase na qual ocorrem inquietações e arroubos desproporcionais. Estas "verdades" em nada auxiliam o adolescente na superação das dificuldades e mudanças que experimenta, tanto no âmbito biológico, como no social e no psicológico, e em suas escolhas, a partir das suas relações com a família e com os grupos sociais, para que sua subjetivação ocorra e avance rumo à idade adulta. Nessa perspectiva, $\mathrm{o}$ presente estudo de revisão da literatura especializada no tema buscou melhor entender a influência da família e dos grupos sociais nos projetos de vida do adolescente, objetivando uma compreensão da adolescência que superasse a visão liberal, naturalista, biologizante e patologizante, que faz com que muitos adultos, e também o próprio adolescente, tenham uma concepção reducionista acerca dessa importante etapa do desenvolvimento humano. Percebeu-se que é possível superar o pensamento determinista sobre o desenvolvimento adolescente, posta a ampla possibilidade de aprendizado a partir das relações que este estabelece com a sociedade, com seus conteúdos historicamente construídos.

Palavras-Chave: Adolescência; Contemporaneidade; Escolhas; Grupos Sociais; Família.
\end{abstract}

\begin{abstract}
Traditional psychological theories emphasize adolescence as a natural stage of development with problems and conflicts proper to human nature. Such conception is contested, for example, by Lev Vygotsky, who considers the historicalsocial process experienced by the individual, influences directly the adolescence, through the changes inserted in society. From the common view, they are absorbed without any personal criticism or alleged "truths", which were built up over time, such as the belief that adolescence is a phase where a disproportionate rapture and great concerns occur. These alleged "truths" do not help the adolescents to overcome moments of difficulties or experienced changes, whether in the biological scope, social or psychological, and in their choices, from their relations with family and with social groups, so that subjectivity occurs and advances towards adulthood. In this perspective, this study, which is specialized in literature review, tried to understand the influence of family and social groups on the adolescents' projects of life, aiming at an understanding of adolescence that surpasses the liberal, naturalistic, biological and pathological view that leads many adults, and also adolescents, to have a reductionist conception about the important stage of human development. It has been realized that it is possible to overcome the deterministic thought over the adolescent development, before a wide possibility of learning from the relations that are set with the society and its historically well constructed contents. Keywords: Adolescence; Contemporaneity; Choices; Social Groups; Family.
\end{abstract}

\section{Introdução}

Quando o assunto é adolescência há um desafio constante para a compreensão, e a aceitação, das escolhas efetivadas nesta fase do desenvolvimento. Há uma grande dificuldade, de um modo geral, dos adultos, assim como do próprio adolescente, em perceber que somos indivíduos históricos, isto é, somos constituídos nas relações sociais e culturais geradas pela humanidade ao longo do tempo, assim como constituímos o outro nestas relações. Esta afirmativa exige de cada um de nós, adulto ou jovem, uma ampla reflexão crítica acerca da constituição e do comportamento do adolescente.

Afiliação dos autores: $\uparrow$ Psicólogo, Graduado pela Universidade Severino Sombra, Vassouras, RJ, Brasil.

\$ Doutora em Psicologia, Professora do Curso de Psicologia da Universidade Severino Sombra, Vassouras, RJ, Brasil.

*fatimaniemeyer@hotmail.com 
"aborrescente" ou adjetivos similares não nos livra de responsabilidades, uma vez que suas escolhas e comportamentos decorrem do contexto no qual está inserido. Portanto, seu comportamento é uma possibilidade de resposta ao mundo ofertado pelos adultos, podendo ser esta uma resposta, por exemplo, de obediência, de respeito, de lealdade e amizade ou de desobediência e desrespeito, dependendo de sentir-se contextualizado ou não, a partir da condição socioeconômica e cultural que vivencia.

Observa-se que as mudanças ocorridas na adolescência têm sido explicadas unicamente de forma metafísica e subjetivista, como pelo Complexo de Édipo de Freud, por exemplo, ou por uma visão apenas biologizante, na qual a adolescência é vista tão somente a partir das inquietações vinculadas à puberdade.

$\mathrm{O}$ adolescente está em pleno desenvolvimento e necessita ter acesso a um referencial crítico para reger as suas escolhas, sendo, portanto, indispensável uma mediação da sociedade como um todo, numa relação dialética. Neste sentido, este estudo objetivou melhor compreender a influência da família e dos grupos sociais nos projetos de vida do adolescente, levando em consideração as características da contemporaneidade, e no sentido de uma não adaptação passiva do comportamento adolescente aos interesses ideológicos particulares dos adultos. Além disso, buscou superar a visão liberal, naturalista, biologizante e patologizante da adolescência, que leva muitos adultos, assim como o próprio adolescente, a uma concepção reducionista dessa etapa do ciclo vital.

Nesse contexto, decidir e fazer escolhas são realidades constantes no dia a dia do adolescente, demandam a elaboração das perdas e prescindem de reflexão. Viver é escolher e as motivações no processo de escolha estão vinculadas às experiências e vivências do indivíduo ao longo do próprio desenvolvimento que, contudo, estão atreladas às características sociais e culturais das influências que o adolescente recebe.

\section{Adolescência}

$\mathrm{O}$ conceito de adolescência surgiu em consequência de um determinado grau, historicamente alcançado, de complexidade da vida social. Não está reduzida apenas a um processo de mudanças biológicas ou naturais, conforme ensina Vygotsky (1996); sem desconsiderar a importância do fator biológico no desenvolvimento psicológico humano, o adolescente é, sobretudo, um ser histórico e social.

Considerada uma fase de transição entre a infância e a juventude, na adolescência ocorrem importantes mudanças, tanto no âmbito social, como biológico e psicológico. Zagury (2002) argumenta que as mudanças que ocorrem no período da adolescência estão diretamente ligadas ao meio cultural onde o adolescente está inserido; portanto, refere-se ao meio, ao convívio e as possibilidades que estão disponíveis e que são capazes de influenciar nesta transição. As mudanças que ocorrem no corpo do adolescente são universais, enquanto que as psicológicas e as de relacionamentos variam de cultura para cultura, de grupo para grupo e até entre indivíduos de um mesmo grupo.

Assim, a adolescência, entendida como uma construção social que influencia diretamente o desenvolvimento da subjetividade, é considerada um fenômeno social. Concomitante ao desenvolvimento fisiológico do corpo, que ocorre de forma involuntária, é um período de maturação de natureza psicossocial, o que inviabiliza a universalização das escolhas do adolescente. Estão implicados nesse processo os aspectos históricos e materiais da vida, caracterizando a adolescência como uma manifestação cultural, que é constituída sob o domínio socioeconômico e cultural das sociedades. Sobre esta afirmativa Bock (2007) argumenta que a concepção sócio-histórica se contrapõe à concepção de base liberal, na qual o homem é concebido a partir da ideia de natureza humana. Seria possuidor de uma natureza que permite, com seu desenvolvimento, que se torne homem, tal qual o conhecemos.

No entender de Bock (2007), as condições material, social e cultural que o ser humano vivencia confere à constituição da sua subjetividade uma origem social. Dessa forma, a adolescência é construída historicamente, estando o seu processo de constituição e duração diretamente dependente de cada meio social em particular. Refere-se a um período de latência social constituída a partir da sociedade capitalista, gerada por questões de ingresso no mercado de trabalho e extensão do período escolar, da necessidade do preparo técnico, além do preparo para a vida adulta.

Omesmoédefendido porOzella(2002,p.23), para quem a adolescência é um período do desenvolvimento "construído socialmente a partir de necessidades sociais e econômicas". Assim, as condições econômicas da família, por exemplo, podem estender ou abreviar o tempo de duração da adolescência, interferindo nas possibilidades das escolhas do adolescente. Este é um ponto importante para o entendimento da não universalização ou naturalização da adolescência, em razão da existência de desigualdades sociais, até mesmo dentro de uma mesma cultura.

A adolescência tem sido vista como um período de difícil entendimento do ser adolescente, tanto da parte dos pais como da sociedade como um todo, em razão de se atribuir a este um comportamento caracterizado apenas por aborrecimentos e dificuldades. No entanto, tanto em Erikson (1987) como em Palacios e Oliva (2004), encontramos que este preconceito estabelecido sobre o adolescente não se fundamenta, uma vez que a sua forma de ser no mundo depende de suas 
relações, estando, portanto, condicionada às condições socioeconômicas e culturais em que está inserido.

Palacios e Oliva (2004) também assinalam que este estágio particular do desenvolvimento humano, situado, aproximadamente, entre os 12 e os 1820 anos de idade, se dá de forma diferente entre os indivíduos e de acordo com a cultura na qual estes são educados. Acrescentam que na adolescência ocorrem transformações físicas e psicológicas importantes, caracterizadas por inquietações e preocupações típicas, diferentes da infância e da fase adulta. Ocorre o desapego familiar em direção aos grupos de iguais e de pessoas de outro sexo e a busca do próprio estilo de vida, de seus valores, modas e hábitos.

Sendo um período psicossociológico dependente da cultura e das suas experiências pessoais, não possui características universais, e os fatores individuais e/ou sociais interferem no desenvolvimento do adolescente. Segundo Palacios e Oliva (2004), não representa um período de graves dificuldades e tensões, o que desconstrói a ideia generalizada da adolescência como tempestade e ímpeto. A competência e a habilidade individual é que irão definir a maior ou menor dificuldade do adolescente em enfrentar e superar as situações e os acontecimentos aos quais está exposto, ladeado, de forma prioritária, pela família.

A puberdade provoca um grande impacto no adolescente, pelo desencadeamento das mudanças físicas provocadas pela ação de hormônios, que interferem no desejo e na atividade sexual, podendo influenciar a agressividade, a instabilidade emocional e a irritabilidade, o que é mediado por fatores sociais, culturais e biológicos (fatores pessoais e contextuais). Este impacto se reflete sobre a sua forma de pensar, de sentir e de agir, com consequências psicológicas e comportamentais, determinando a atitude do adolescente e sua reação diante das mudanças. Este passa a demonstrar maior autonomia e um raciocínio mais complexo, embora passível de distorções e de erros pela nova visão de mundo e pela influência do contexto social e cultural. Também a organização da personalidade é influenciada pelas vivências nos níveis físico, cognitivo e social, processo que exige do adolescente a aceitação de sua imagem corporal, a decisão sobre propostas ideológicas e religiosas, a escolha de uma profissão, o assumir uma orientação sexual, valores morais, estilo de vida e de relações etc. (PALACIOS e OLIVA, 2004)

Erickson (1987) institucionalizou a adolescência a partir do conceito de moratória psicossocial, de espera pelos compromissos adultos, caracterizada pela tolerância seletiva por parte da sociedade e uma atividade lúdica por parte do adolescente. Defende a ideia de que cada sociedade e cada cultura determinam certa moratória para os seus jovens e, por conseguinte, seus hábitos são condizentes com os valores dessa sociedade. Para o autor, no período da moratória psicossocial o jovem, "através de livre experimentação de papel, poderá encontrar um nicho em alguma seção da sociedade, um nicho que é firmemente definido e, entretanto, parece ser exclusivamente feito para ele" (p.157).

Quandoo adolescentenão experimenta amoratória ocorre uma evolução incompleta, entrando muito rapidamente na vida adulta, sem um amadurecimento interior. Como consequência, pode se sentir isolado, vazio, ansioso e indeciso, resultando numa dificuldade de interação com pessoas significativas, escolhidas por ele como parte integrante da construção da sua identidade adulta, podendo culminar numa identidade difusa, caracterizada por incoerência; ou o mesmo pode optar por identidades que são indesejáveis para a família e para a sua comunidade. (ERIKSON, 1987)

Também Calligaris (2000) considera a adolescência como um período de desenvolvimento moratório e ressalta as dificuldades do adolescente de obter apoio para a superação da moratória. Na falta de vislumbrar uma possibilidade "do que ser", o adolescente torna-se um intérprete dos desejos adultos, embasando a falsa concepção do senso comum de que a adolescência é uma fase difícil e problemática da vida, de características negativas, inundada de "bobagens próprias da idade".

Mas é na adolescência que o indivíduo passa a experimentar novas possibilidades para as quais ele era, até então, indiferente, e se encontra ansioso por novos modelos de identificação, em razão do distanciamento de seus pais. Nesse momento, a busca por novas identificações, seja de pessoas ou de ideais, se dá por uma crise de identidade decorrente das mudanças físicas, psíquicas e sociais, e ocorre a legitimação da confiança em si e nos outros, sendo a interação grupal uma opção de proteção diante das angústias e temores próprios deste período. (ERIKSON, 1987)

A resolução positiva da crise de identidade se dará a partir do apoio das pessoas de seu convívio, representando um ganho psicológico, emocional e social para a formação de uma personalidade adulta de equilíbrio mental e de bom relacionamento social. Inversamente, se não obtém respostas para suas questões, a resolução da crise se dará de forma negativa, reforçando o desajuste social e a tendência à ansiedade e ao fracasso. Isso, no entanto, é reversível diante de novas vivências, que poderão refazer o equilíbrio e o ajustamento ao novo contexto social e histórico em que está inserido. (ERIKSON, 1987)

Knobel (2003) identificou a "síndrome normal da adolescência", umconjuntodecaracterísticas ou sintomas próprios desse período do desenvolvimento: busca de si mesmo e da identidade; tendência grupal; necessidade de intelectualizar e fantasiar; crises religiosas, que podem ir desde o ateísmo mais intransigente até o 
misticismo mais fervoroso; deslocalização temporal, em que o pensamento adquire as características de pensamento primário; evolução sexual manifesta, desde o autoerotismo até a heterossexualidade genital adulta; atitude social reivindicatória com tendências anti ou associais de diversas intensidades; contradições sucessivas em todas as manifestações da conduta, dominada pela ação, que constitui a forma de expressão conceitual mais típica deste período da vida; separação progressiva dos pais; e constantes flutuações de humor e do estado de ânimo.

\section{Formação da subjetividade e da personalidade na contemporaneidade}

O período contemporâneo, também chamado de pós-moderno, se iniciou após a Segunda Guerra Mundial e encerra uma nova percepção do mundo em relação à modernidade, onde se constatam rápidas transformações no comportamento humano, no mercado e nos avanços tecnológicos e científicos, trazendo, como consequência, ambiguidades, conflitos e outras situações específicas, como o pluralismo, a globalização, a cultura de massa, a saturação social, e o consumismo, entre outras, com influências diretas sobre a subjetividade das pessoas. Este contexto se reflete sobre o adolescente, cuja personalidade, muitas vezes considerada hedonista, narcisista e marcada pela falta de sentido existencial, caracteriza-se pela angústia e pela ansiedade e visto com uma atitude geral de "aborrecimento".

Segundo Berger e Luckmann (2004), o pluralismo, definido como a existência concomitante de várias visões de mundo, ocorre pela multiplicidade e continuidade de informações que chegam até as pessoas. O pluralismo produz a "cultura de massa", que, segundo Bosi (2000), reúne imposições ditadas pelos meios de comunicação, muitas vezes identicamente destinadas às mais diferentes regiões e povos, que impactam as massas, estejam onde estiverem, produzindo a mesma arte, vestindo as mesmas roupas, gostando das mesmas comidas etc., numa interferência direta na cultura peculiar de cada povo. A massificação e a homogeneização do conhecimento e da percepção da realidade interferem de forma direta e intensa na formação da subjetividade.

Observa-se uma disposição das pessoas para se sujeitar às mídias eletrônicas, ao domínio dos mercados (econômico, político, cultural e social), ao consumo pelo consumo, à pluralidade cultural e à polarização social, entre outras. Há uma valorização do relativismo e da indiferença, com "predomínio do instantâneo, da perda de fronteiras, do mundo virtual, da imagem, do som e do texto em velocidade instantânea". (OLIVEIRA, 2001, p.22) Mo Sung (2002) cita que, atualmente, a mídia provoca desejos que nem sempre estão próximos da realidade do adolescente. E, para
Viotti (1995), na realidade virtual o adolescente experimenta superexcitação da sensibilidade (nos celulares, televisão e computadores), desvio do real, isolamento e indiferença, e busca nas fantasias o ideal de ser humano.

Giddens, Lash e Beck (2012) argumentam que as características próprias da contemporaneidade impactam de forma decisiva a vida das pessoas em seu contexto geográfico, social e cultural. Como exemplo, citam a valorização do narcisismo e do hedonismo, que resulta em pessoas excessivamente individualistas, cujo foco é o culto ao prazer, ao corpo e à aparência.

Nesse contexto, a formação da subjetividade e da personalidade do adolescente são impactadas por todas as características dessa contemporaneidade. Bock (2004) se refere à subjetividade como aquilo que diz respeito ao indivíduo, ao seu psiquismo ou a sua formação, ao seu mundo interno, que é composto pelas emoções, sentimentos e pensamentos. É a subjetividade que constitui a singularidade de cada pessoa, que a torna única.

Vygotsky (1995) aponta para a origem da subjetividade nas relações sociais do indivíduo e se constitui pela troca continuada entre o interno e o externo, num processo que transforma o indivíduo em um ser singular, único, em relação às possibilidades construídas pela humanidade. Resulta das relações originadas nas condições sociais e materiais de cada um e pela forma como se relaciona com o ambiente e com os outros semelhantes, pelas quais percebe e representa a realidade de forma única. A subjetividade é produto da integração da evolução biológica e ontológica do indivíduo, permitindo o desenvolvimento da singularidade e do psiquismo.

Giddens (2002), assinala que a subjetividade no mundo contemporâneo é fortemente influenciada pela ansiedade permanente que afeta as pessoas, dada a necessidade de organização das inúmeras informações recebidas do seu meio social e, principalmente, profissional, e o esvaziamento do sentido de uma vivência subjetiva. Ressalta que a falta de um sentido pessoal, com a permanente sensação de que a vida não tem nada a oferecer, é um fato psíquico marcante da pós-modernidade, produtor de uma insegurança capaz de provocar a desestabilização da personalidade, cuja identidade pode ser de uma pessoa light, sem conteúdo, direcionada ao sucesso, ao dinheiro, ao poder e ao gozo ilimitado, sem restrições.

O impacto da cultura de massa que produz o individualismo e a homogeneização acarreta a perda da originalidade e da criatividade, de pensamento e opinião, tornando as pessoas superficiais e fugazes, susceptíveis às opiniões externas, como as expostas nos meios de comunicação e nas teorias momentâneas.

Segundo Portela (2008) vive-se novas formas de se estabelecer relações, que afetam a formação 
da subjetividade, provocando o surgimento de um novo sujeito. É o caso do consumismo que marca a contemporaneidade - para ser é preciso ter, implicando novos modos de relacionamento, acompanhados da desvalorização das tradições culturais e da constituição de indivíduos insatisfeitos, sem referências estáveis. Hall (2006) também fala do sujeito contemporâneo constituído diante da perda de um sentido estável de si próprio, resultando na construção de identidades fragmentadas a partir da pluralidade e da rapidez das mudanças que respondem às demandas culturais da pós-modernidade. O indivíduo convive com múltiplas e instáveis identidades possíveis, se identificando temporariamente com uma ou outra, não havendo uma identidade fixa, imutável, mas sim uma pluralidade de identificações a partir das diferentes possibilidades disponibilizadas pela cultura contemporânea. No entanto, enfatiza que, mesmo fragmentado, o indivíduo "vivencia sua própria identidade como se ela estivesse reunida e 'resolvida', ou unificada" (p. 38).

Por outro lado, Birman (2000) argumenta que a atual subjetividade se constitui com a valorização do olhar do outro, tanto socialmente quanto pelo poder da mídia, com a formação de individualidades a partir de objetos e informações descartáveis e descomprometidas, levando ao esvaziamento do indivíduo e a uma individualidade voltada para a exaltação de si mesmo. Conforme Giddens (2002), o indivíduo está envolvido por um casulo protetor, para se proteger e se isolar, sendo o narcisismo uma patologia do comportamento contemporâneo, pois acompanha o modo mercantilizante e consumista da atualidade. "O consumismo se utiliza do narcisismo, na medida em que promete as coisas mesmas que o narcisismo deseja (charme, beleza e popularidade), através do consumo dos tipos certos de bens e serviços" (p. 8).

Para Bauman (2001) a vida organizada em torno do consumo é orientada pela sedução, por desejos sempre crescentes e voláteis, por uma sede constante de novas sensações que devem ser absorvidas e experimentadas. A subjetividade contemporânea é fluida, própria de um indivíduo líquido e inacabado, que experimenta a consequente insegurança do "mundo líquido" que deixa os indivíduos desamparados, livres a novas escolhas e exterioridades num mundo em constante transformação. Bauman (2005) traz a ideia de fragmentação do indivíduo e falência do coletivo, com a primazia do indivíduo livre para as escolhas e à sua própria sorte. E, de acordo com Giddens (2002), as influências dos variados encontros e diferentes meios de convivência promovem a fragmentação da subjetividade, requerendo, em cada um, uma forma diferente de comportamento adequado. Quando o indivíduo sai de um encontro e entra em outro naturalmente organiza a sua apresentação à exigência da nova situação.

A formação da personalidade é uma objetivação da individualidade, resultante da relação do indivíduo com o mundo, cuja origem é endopsíquica (funções psicológicas superiores e temperamento) e exopsíquica (experiências vividas pelo indivíduo na sociedade). "Em sua gênese, a personalidade resulta de relações dialéticas entre fatores externos e internos sintetizados na atividade social do indivíduo" (MARTINS, 2001, p.176-177). Os fatores externos são as condições sociais (materiais) e os fatores internos são as condições subjetivas, que se referem à materialidade biológica e psicológica do indivíduo. A personalidade, dessa forma, é o resultado de um duelo entre o indivíduo e a sociedade, em que o indivíduo se constitui de forma diferente da sociedade a partir de sua ação e de seu modo de existir. A personalidade é um "produto da atividade individual condicionada pela totalidade social".

Por sua vez, Forghieri (2015) define a personalidade como o conjunto das características do existir humano, consideradas e descritas a partir da maneira como são percebidas e compreendidas pelo indivíduo ao longo da existência cotidiana imediata, fundamentadas nos seus aspectos fenomenológicos primordiais. Dado que o ser humano não pode ser fora do mundo, seus pensamentos, sentimentos e ações têm como ponto de partida essa vivência concreta. As suas características de personalidade assinalam o seu potencial de ajustamento no mundo contemporâneo, podendo ou não escolher como valores o narcisismo, o individualismo ou o hedonismo, dado que são oferecidos e não impostos. E os desafios do mundo contemporâneo não superam a capacidade do indivíduo de ocuparse deles através das potencialidades disponíveis na estrutura da sua personalidade.

Segundo Martins (2001), a personalidade se desenvolve a partir "das especificidades dos vínculos do indivíduo com o mundo, do grau e organização da hierarquia de atividades em relação aos motivos e do grau de subordinação desta organização à consciência sobre si e autoconsciência". Essa hierarquia indica as atividades prioritárias no desenvolvimento do indivíduo, responsáveis pelas mudanças mais significativas nos processos psíquicos e na personalidade e de onde se originam outros tipos de atividade. $\mathrm{E}$ a autoconsciência permite ao indivíduo refletir sobre sua existência enquanto ser social e ser do gênero humano, além de compreender as suas possibilidades e os seus limites.

Observamos, assim, que a construção da personalidade do indivíduo se dá a partir das afinidades entre os motivos e os fins distintos, de acordo com as suas necessidades. E o desenvolvimento da consciência da realidade só é possível por meio da subjetividade, base da constituição do psiquismo, formada pela individualidade (herança genética e características biológicas) e pela forma objetiva de vida desse indivíduo. Durante o desenvolvimento o indivíduo ganha singularidade - a sua individualidade -, e pela complexificação desta há a 
constituição da personalidade.

Na contemporaneidade, marcada pela "liquidez" das relações, pelo consumismo epela globalização, omeio sociocultural em que o indivíduo está inserido interfere diretamente em sua subjetividade e individualidade e, por consequência, no seu comportamento individual. Portanto, o comportamento do adolescente, de forma especial, sofre as mesmas interferências, principalmente da família e dos grupos sociais, na definição de suas escolhas.

\section{Implicações dos grupos sociais e da família nas escolhas do adolescente}

Do ponto de vista da Sociologia, Giddens (2008, p. 693) define grupo social como "o conjunto de indivíduos que interagem de modo sistemático uns com os outros". Variam de tamanho, podendo ir de pequenas associações a grandes organizações ou sociedades, compartilhando a característica de os seus membros terem consciência de uma identidade comum. A maioria das pessoas pertence a diferentes e numerosos tipos de grupos, passando grande parte da vida em atividades grupais.

Entre estes grupos, em se tratando do adolescente, principalmente a convivência com a família e com o grupo de pares tem implicações decisivas em suas escolhas, não ignorando a importância da participação dos demais grupos na constituição da sua subjetividade e personalidade.

Caracterizada pela possibilidade do indivíduo se posicionar diante da sociedade como pessoa com direitos e deveres, num processo de formação de identidade, a adolescência é marcada por sonhos e desejos e pela busca constante de respostas, que muitas vezes não obtém, devido à falta de preparo da escola, da sociedade ou da própria família, desorientadas diante das questões da contemporaneidade. Neste contexto de vida, o adolescente é impulsionado a decidir sobre um projeto de vida, o que vai the permitir acumular experiências nas relações com o outro e com o mundo, formando-se enquanto sujeito consciente e crítico. (NASCIMENTO, 2006)

O projeto de vida indica uma possibilidade de futuro, uma proposta de movimento através da temporalidade, uma possibilidade de vir a ser, conforme apresenta Ciampa (2015), onde as possíveis identidades futuras expressam a inesgotável plasticidade do humano. A constituição de uma identidade a partir de suas relações sociais, proporciona ao adolescente construir uma história de vida e, por consequência, um projeto de vida aberto à mudança. Soares (2002) explica que o futuro é preparado a partir do passado e do presente e, assim, o projeto de vida envolve uma atitude que antecipa, organiza e regula as principais atividades e comportamentos do indivíduo.

Ainda sobre o projeto de vida, Velho (2003) o define como um jeito do indivíduo se comunicar, uma forma de anunciar seus interesses, aspirações e objetivos, permitindo dar sentido e orientar a sua vida. Para Quevedo (2001, p.15), "projeto" tem o significado de algo que é "lançado para diante", indicando a ideia de uma situação ou estado que se quer alcançar no futuro. É um plano que antecede e prepara a execução ou a realização da ação projetada, um sinal dado pelo adolescente que formou sua identidade, relacionouse com o grupo e é capaz de notificar seus sonhos e desejos, suas opções pessoais.

Entretanto, o senso comum tem como tendência focar apenas as características negativas do adolescente, delineando um perfil preconceituoso e estigmatizado. Teixeira (2005) aponta para uma discussão emblemática sobre o jovem, a escola e a família; alerta, porém, para o fato de não se dar a devida importância ao que ele realmente pensa, como vive e sobre qual é a sua representação das instituições que fazem parte da sua vida, uma vez que é a partir deste entendimento que pensa seu futuro, o que quer, o que anseia e, sobretudo, como pretende se realizar no campo pessoal e profissional.

Teixeira (2005) comenta que os jovens são exímios sonhadores e sabem verbalizar estes sonhos; contudo, por vezes, não conseguem estabelecer uma relação destes com o presente, nem conseguem dizer o que precisam fazer no hoje para realizá-los no futuro; ou seja, não conseguem identificar as relações que existem entre o hoje e o amanhã.

Tal argumentação permite entender a importância do exercício da cidadania pelo adolescente. Porém, a vida contemporânea nem sempre permite a realização de todas as suas capacidades em direção à autorrealização. Isto, por si só, impede uma participação efetiva do adolescente na sociedade, uma vez que muitas vezes é destituído de sua identidade quando o denominamos "aborrescente", inconsequente, incoerente ou dependente.

Se é na construção da identidade que se articulam os aspectos psíquicos, sociais e políticos, que faz surgir o indivíduo cidadão capaz de assumir a própria existência, a autoestima, o autoconceito e a autoconfiança permitirão uma visão destemida do futuro e a elaboração de um projeto de vida, que produz um sentido de vida, um olhar otimista para a superação dos obstáculos, rumo à autorrealização. Neste contexto, se revela a importância da família e dos grupos sociais para a concretização do projeto de vida do adolescente, fruto das escolhas que definirão a sua vida.

"A família é um entre os vários facilitadores ou dificultadores do processo de escolha, mas antes de tudo tem um papel importante na realidade do adolescente e deve ser levada em consideração quando se trata de projeto de vida" (SANTOS, 2005, p.63). A influência 
da família sobre o projeto de vida do adolescente se dá através de suas "opiniões" e do "sentimento gerado pelas opiniões", muitas vezes representando os seus próprios sonhos que não puderam ser concretizados. Assim, o projeto de vida do adolescente é influenciado, de forma especial, pelas relações familiares, além dos amigos e do contexto escolar. É a família que, desde o início da sua vida, dá a sustentação necessária ao adolescente, sendo a base de sua educação moral e de valores, the fornecendo exemplos para a convivência social e para o estabelecimento das amizades, que permitirão o convívio com os outros indivíduos e uma tomada de decisão para a escolha profissional e para a realização pessoal. E, conforme Steinberg (2005), é função dos pais querer influenciar a personalidade de seus filhos; porém, com o passar do tempo, esta influência deve diminuir para que tenham oportunidades de desenvolver as habilidades das quais necessitam para se descobrirem.

Segundo Nolte e Harris (2005), para o adolescente a casa da família deveria representar um porto seguro, um lugar onde pudesse ser autêntico, onde não sofresse qualquer tipo de restrição, numa atmosfera acolhedora, fundamental para o seu fortalecimento e ganho de resistência para lidar com os altos e baixos da vida. No entanto, para Fierro (2004), a família pode influenciar de forma positiva ou negativa a personalidade do adolescente, dependendo do modo como instrui e decide. Em nome de uma suposta felicidade do filho, muitas vezes os pais decidem no lugar dele ou, ao contrário, abdicam de sua missão de autoridade e de conhecimento, deixando de ser a referência fundamental que o adolescente necessita. Libanio (2004, p.169), afirma que "os pais são pais e não colegas, nem amigos de grupos dos filhos".

Garcia (2005) argumenta que durante a adolescência o indivíduo busca uma complementação de sua intimidade e esta se dá através dos grupos, em razão da sua similaridade, seja de idade, gênero, etnia, religião, nível sócio-econômico-cultural ou atividades. O grupo social é o espaço onde o adolescente experimenta confiança, segurança e status, podendo ser a escola, a igreja, os locais para atividades esportivas, entre outros, e são formados a partir de relações estáveis entre os indivíduos que possuem interesses e objetivos em comum. Os amigos cumprem importante papel na vida do adolescente, dando apoio social e emocional, permitindo a manutenção de sua saúde física e mental, prevenindo sentimentos de angústia social e diminuindo os impactos referentes às discórdias familiares.

Lacerda e Lacerda (1998) apontam para a importância dos amigos para o adolescente, como fonte de companhia, intimidade e apoio emocional; contudo, a família ainda é importante, cada qual desempenhando papéis diferentes, mas complementares. Com os pares, o adolescente compartilha experiências novas, cabendo à família ser um ponto de segurança estrutural, no sentido de permitir que explore o mundo novo que se apresenta.

A forma como ocorre a emancipação em relação à família, segundo Fierro (2004, p. 300), é diferente para cada adolescente, dependendo das práticas de criação, que diferem de uma família para outra. Também cada família favorece a autonomia dos filhos de uma forma particular, com maior ou menor ocorrência de atritos familiares. Embora continue forte a influência dos pais sobre os filhos, e decisiva nas escolhas e valores, aos poucos o adolescente se distancia da casa familiar, com diminuição da comunicação entre eles como busca de uma maior independência, rumo a relacionamentos mais próximos com o grupo de amigos.

Fierro (2004) afirma, ainda, que as contradições entre os valores do grupo e aqueles reforçados pela família contribuem para que o adolescente expresse algumas características superficiais, como a forma de se vestir, a preferência por um estilo geral de vida, sem influenciar, contudo, de forma pragmática, as opções e os valores decisivos de vida. No que se relaciona a decisões sobre o futuro, é comum o adolescente adotar a orientação dos pais e, quanto ao presente e a realização de desejos e necessidades atuais, seguir os ideais de seus pares.

Zimerman (2004, p. 360-361) alerta para uma certa tendência antissocial dos grupos de adolescentes que, na imensa maioria das vezes, é uma fase transitória. Contudo, sob a influência do grupo, o adolescente pode expressar " [...] acessos de ódio, gestos de brutalidade, atitudes de desconsideração cruel para com as pessoas, ausência de responsabilidade pelos próprios atos", geralmente, para ser aceito pelo grupo.

A busca do adolescente por uma maior independência, maturidade e o compartilhamento dos conflitos vivenciados na família ocasionam um desprendimento dos pais e um reforço das relações com outras pessoas fora do contexto familiar, principalmente em busca de apoio nos amigos, visto por Outeiral (2003) como positivo para esta fase de desenvolvimento.

Zimerman (2004) chama a atenção para as vivências em grupo como relevante para a "constituição de uma nova identidade, intermediária entre a família e a sociedade, com a assunção e o exercício de novos papéis", e para a valorização do indivíduo como pessoa. Portanto, o conhecimento dos grupos aos quais o adolescente pertence é importante para se compreender sua identidade e as direções das suas escolhas.

\section{Considerações Finais}

Marcada pela crise de identidade e com foco no futuro, a adolescência é um momento no qual muitas escolhas são feitas e projetos começam a ser construídos a partir da visão do próprio adolescente, dependendo 
do que ele pensa de si mesmo, de suas qualidades e perspectivas, logo, das vivências e experiências acumuladas em sua história de vida. O projeto de vida é constituído pelo adolescente, em geral, priorizando estudar/formar e ter uma profissão/emprego, seguidos de ter amigos e construir uma família. Esta priorização demonstra a seriedade desta fase do desenvolvimento e sua relevância para o direcionamento de suas escolhas para o futuro e, na atualidade, para satisfazer o desejo de se sentir amado, independente e aceito socialmente.

Os projetos de vida "falam" da busca de seus sonhos e ideais, a partir de uma subjetividade produzida em todos os âmbitos da vida do adolescente, que se materializa no dia a dia nas relações que estabelece, sejam elas familiares ou com os pares. Embora as escolhas em seus projetos de vida sejam sempre pessoais e reguladas pela personalidade do adolescente, sofre influências da família e dos grupos sociais e de amigos, entre outros. A personalidade do adolescente interfere diretamente na relação pai-filho e na identificação e associação a grupos de pares e amigos, facilitando ou dificultando a realização de seus projetos de vida.

A atuação parental tem papel fundamental nas escolhas do adolescente, uma vez que este requer de seus pais que a sua opinião seja levada em consideração, solicitando o diálogo. A família deve proporcionar o apoio necessário para a elaboração dos projetos de vida do adolescente, esclarecendo sobre as metas necessárias para a sua concretização, ensinando como encarar os desafios e os riscos do mundo, estimulando a confiança, agregando motivos para que este valorize a própria vida, alertando sobre o que é imediato e o que é passageiro e sobre o que faz ou não faz sentido para o seu projeto de vida. No entanto, a família pode facilitar ou dificultar o processo de escolha, pois, muitas vezes, os projetos dos pais é que são apoiados como projetos para o futuro do filho, carreando objetivos seus que não puderam ser realizados.

Aescolha dos amigos e dos pares pelo adolescente, que se dá a partir de afinidades e semelhanças, pode repercutir de forma positiva ou negativa em seu desenvolvimento, pela adoção de práticas sociais ou antissociais. A influência dos grupos sociais, gradativamente, ao longo da adolescência, pode ser reforçada pelos seus princípios mais flexíveis que os da família e, em geral, sem o predomínio de exigências e cobranças na realização de planos ou tarefas, exceto com relação à traição e à indiscrição. As amizades permitem a elaboração e a reelaboração da personalidade, de diversos comportamentos, sentimentos e atitudes frente às situações da vida, auxiliando uns aos outros para 0 alcance de seus objetivos.

Assim, diretamente dependente de um contexto em modificação permanente na contemporaneidade, sem desconsiderar sua natureza biológica, a adolescência não se resume apenas à trajetória individual do adolescente, devendo ser apreciadas as variáveis familiares e sociais que se refletem nas escolhas e no comportamento do adolescente, que em geral denunciam as demandas deste contexto em que está inserido. O "mundo líquido" revela, de um lado, o desamparo, mas, de outro, a liberdade para novas escolhas, trouxe novas possibilidades de prazer (gerador de felicidade), mas também a urgência, o agora. E esse cenário faz dos adolescentes um dos grupos mais sensíveis aos problemas da contemporaneidade.

\section{Referências}

BAUMAN, Zygmunt. Modernidade líquida. Rio de Janeiro: Jorge Zahar, 2001.

Identidade. Rio de Janeiro: Jorge Zahar, 2005.

BERGER, Peter L.; LUCKMANN, Thomas. Modernidade, pluralismo e crise de sentido: a orientação do homem moderno. Petrópolis, RJ: Vozes, 2004.

BIRMAN, Joel. Mal-estar na atualidade: a psicanálise e a novas formas de subjetivação. 2. ed. Rio de Janeiro: Civilização Brasileira, 2000.

BOCK, Ana Mercês Bahia. A perspectiva histórica da subjetividade: uma exigência para a psicologia atual. Psicologia América Latina, São Paulo, n.1, 2004.

A adolescência como construção social: estudo sobre livros destinados a pais e educadores. Revista Semestral da Associação Brasileira de Psicologia Escolar e Educacional (ABRAPEE), São Paulo, Volume 11, 2007.

BOSI, Eclea. Cultura de massa e cultura popular. Rio de Janeiro: Vozes, 2000 .

CALLIGARIS, Contardo. A adolescência. São Paulo: Publifolha, 2000.

CIAMPA, Antonio da Costa. A estória do Severino e a História da Severina: um ensaio de Psicologia Social. São Paulo: Brasiliense, 2015.

ERIKSON, Erik Homburger. Infância e Sociedade. 2. ed. Rio de Janeiro: Zahar, 1987.

FIERRO, Alfredo. Relações sociais na adolescência. In COLL, César; PALACIOS, Jesús; MARCHESI, Álvaro. Desenvolvimento psicológico e educação: Psicologia evolutiva. 2. ed. Porto Alegre: Artmed, 2004

FORGHIERI, Yolanda Cintrão. Psicologia fenomenológica: fundamentos, método e pesquisas. São Paulo: Cengage Learning, 2015.

GARCIA, Agnaldo. Psicologia da amizade na infância: Uma revisão crítica da literatura recente. Interação em Psicologia, v. 9, n. 2, 2005.

GIDDENS, Anthony. Modernidade e identidade. Rio de Janeiro: Zahar, 2002.

Sociologia. 6. Ed. Lisboa: FUNDAÇÃO CALOUSTE GULBENKIAN, 2008

; LASH, Scott; BECK, Ulrich. Modernização reflexiva: política, tradição e estética na ordem social moderna. 2.ed. São Paulo: UNESP, 2012.

HALL, Stuart. A identidade cultural na pós-modernidade. 11. ed. Rio de Janeiro: DP\&A, 2006.

KNOBEL, Maurício. A Síndrome da adolescência normal. In A. Aberastury; M. Knobel. Adolescência normal. Porto Alegre: Artmed, 2003.

LACERDA, Catarina Augusta de Oliveira Pasin de; LACERDA, Milton Paulo de. Adolescência: problema, mito ou desafio? 2. ed. Petrópolis, RJ: Vozes, 1998.

LIBANIO, João Batista. Jovens em tempo de pós-modernidade: considerações socioculturais e pastorais. São Paulo: Loyola, 2004. 
MARTINS, Lígia Márcia. Análise sócio-histórica do processo de personalização de professores. Tese de Doutorado. Programa de Pósgraduação em Educação, Faculdade de Filosofia e Ciências, UNESP. Marília, 2001 .

MO SUNG, Jung. Sujeito e sociedades complexas: para repensar os horizontes utópicos. Petrópolis: Vozes, 2002.

NASCIMENTO, Ivany Pinto. Projeto de vida de adolescentes do ensino médio: um estudo psicossocial sobre suas representações. Imaginario, São Paulo, v.12, n.12, 2006

NOLTE, Doroty Law; HARRIS, Rachel. Os adolescentes aprendem o que vivenciam. Rio de Janeiro: Sextante, 2005.

OLIVEIRA, Joselina Luzia Menezes. Viver os votos em tempos de pósmodernidade. São Paulo: Loyola, 2001.

OUTEIRAL, José. Adolescer: Estudos Revisados sobre Adolescência. 2. ed. Rio de Janeiro: Revinter, 2003.

OZELLA, Sérgio. Adolescência: uma perspectiva crítica. In: Adolescência e psicologia - concepções práticas e reflexões críticas. Brasília: Conselho Federal de Psicologia, 2002.

PALACIOS, Jesús; OLIVA, Alfredo. A adolescência e seu significado evolutivo. In: Coll, César; MARCHESI, Álvaro; PALÁCIOS, Jesús. Desenvolvimento psicológico e educação. 2. ed. Porto Alegre: Artmed, 2004

PORTELA, Marco Antônio. A crise da psicologia clínica no mundo contemporâneo. Estud. psicol., Campinas, v. 25, 2008.

QUEVEDO, Luis Gonzales. Projeto de vida: amar e ser amado. São Paulo: Loyola, 2001.

SANTOS, Larissa Medeiros Marinho dos. O papel da família e dos pares na escolha profissional. Psicologia em Estudo, Maringá, SP, v. 10, n. 1, 2005.

SOARES, Dulce Helena Penna. A escolha profissional: do jovem ao adulto. São Paulo: Summus, 2002.

STEINBERG, Laurence. 10 Princípios Básicos para educar seus filhos. Rio de Janeiro: Sextante, 2005.

TEIXEIRA, Elaine Juncken. Juventude pobre, participação e redes de sociabilidade na construção do projeto de vida. Dissertação (Mestrado em Psicologia). Rio de Janeiro: Universidade Federal do Rio de Janeiro, 2005.

VELHO, Gilberto. Projeto e metamorfose: antropologia das sociedades complexas. 3. Ed. Rio de Janeiro: Jorge Zahar, 2003.

VIOTTI, Frederico Romanini de Abranches. Origem e Fundamento da Mística Pós-moderna. Monografia Curso em Ciência Política. Brasília: Universidade de Brasília, 1995.

VYGOTSKY, Lev Semióyonovich. Obras escogidas. Tomo III. Madrid: Visor/MEC, 1995.

Obras escogidas. Tomo IV. Madri: Visor/MEC, 1996.

ZAGURY, Tânia. Limites sem trauma: construindo cidadãos. Rio de Janeiro: Record, 2002.

ZIMERMAN, David E. Manual de Técnica Psicanalítica. Porto Alegre: Artmed, 2004. 